\title{
A Conceptual Design of a Short Takeoff and Landing Regional Jet Airliner
}

\author{
Andrew S. Hahn ${ }^{1}$ \\ NASA Langley Research Center, Hampton, VA, 23681
}

\begin{abstract}
Most jet airliner conceptual designs adhere to conventional takeoff and landing performance. Given this predominance, takeoff and landing performance has not been critical, since it has not been an active constraint in the design. Given that the demand for air travel is projected to increase dramatically, there is interest in operational concepts, such as Metroplex operations that seek to unload the major hub airports by using underutilized surrounding regional airports, as well as using underutilized runways at the major hub airports. Both of these operations require shorter takeoff and landing performance than is currently available for airliners of approximately 100-passenger capacity. This study examines the issues of modeling performance in this now critical flight regime as well as the impact of progressively reducing takeoff and landing field length requirements on the aircraft's characteristics.
\end{abstract}

\section{Nomenclature}

$\begin{array}{ll}C T O L & =\text { conventional takeoff and landing } \\ F A A & =\text { Federal Aviation Administration } \\ F A R & =\text { Federal Aviation Regulation } \\ R J & =\text { regional jet } \\ S T O L & =\text { short takeoff and landing } \\ U C D & =\text { three-dimensional Weissinger lifting line aerodynamics program }\end{array}$

\section{Introduction}

$\mathrm{D}$ EMAND for air travel over the next fifty to seventy-five years has been projected to be as high as three times that of today. Given that the major airport hubs are already congested, and that the ability to increase capacity at these airports by building more fullsize runways is limited, unconventional solutions are being considered to accommodate the projected increased demand. Two possible solutions being considered are: Metroplex operations, and using existing underutilized runways at the major hub airports. Both of these solutions depend on the availability of short takeoff and landing (STOL) aircraft.

One version of the Metroplex concept is to offload operations of aircraft below approximately 100 seats from the major hub airports to already existing regional airports. This would allow airlines to take advantage of additional runways and airspace that is currently underutilized. The shift of smaller aircraft operations to smaller, regional airports would free up the long runways at the major hub airports for operations of much larger aircraft. This shift would have the effect of

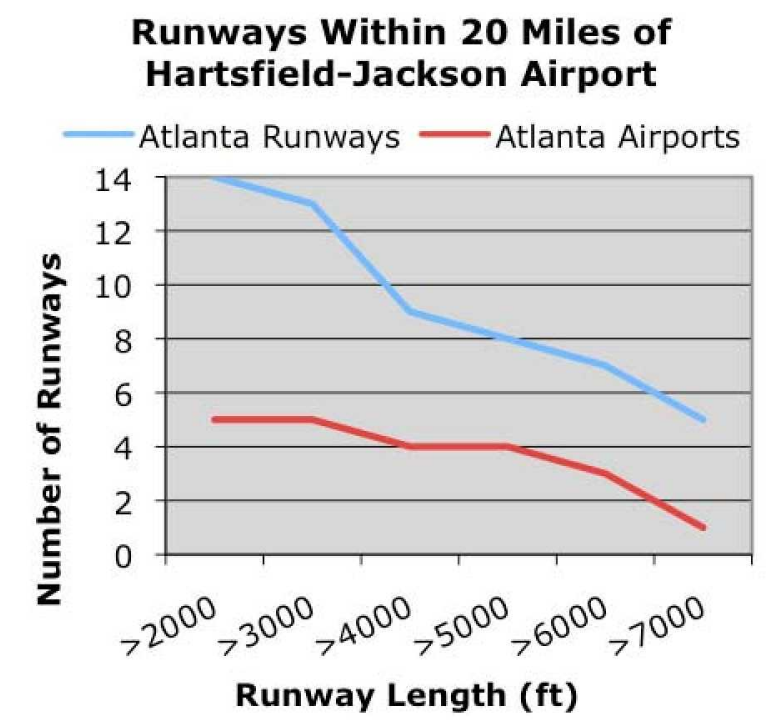

Figure 1. Atlanta Metroplex runway lengths

\footnotetext{
${ }^{1}$ Aerospace Engineer, Aeronautics Systems Analysis Branch, Mail Stop 442, AIAA Member 193989.
} 
increasing both the passenger and operations capacity throughout the Metroplex. It would also have the local effect of increasing passenger capacity at the major hub airports, even though operations capacity is unchanged there. Since these regional airports typically have shorter runways, STOL performance is required. Consideration of the Atlanta metropolitan area indicated that the capability to operate out of runways as short as 3000 feet would increase the available number of runways from 7 to 13 (Fig. 1) ${ }^{1-5}$ The major attraction of this concept is that the number of runways could be doubled without the need to develop significant new physical infrastructure, and the approach and departure procedures are already in place. These advantages could dramatically shorten practical Metroplex implementation times. Essentially, the majority of the infrastructure would be available as soon as the aircraft with the necessary takeoff and landing performance were available.

A similar result is found for the concept of using underutilized, existing runways at the major hub airports. Generally, these runways were used by small turboprop commuter-liners and became underutilized as these aircraft lost favor. Since these aircraft typically could use runways of between 3000 and 4000 feet, those lengths are generally available. Once again, very little additional infrastructure is required, and all of the approach and departure procedures already exist.

While there are a great many issues to be addressed regarding whether there really are airspace capacity advantages to these concepts, it seems reasonable to examine what the impacts of requiring STOL capability down to a $\mathbf{3 0 0 0}$ foot runway length would have on the aircraft itself.

In order to identify key requirements for the design of a STOL regional jet (RJ), I looked at the current fleet of $\mathrm{RJ}$ 's and identified trends of increasing size and design range. These trends have emerged because it is more economical to fly a full RJ on some long, thin routes than it is to fly a partially full single-aisle airliner such as the Boeing 737. The flexibility that comes from having longer-range is very desirable from an airline operations standpoint, even if it results in a somewhat more expensive aircraft to own and operate. Unfortunately, long-range and short takeoff are competing performance parameters. Since the takeoff field length is dominated by thrust-toweight ratio, and the takeoff weight for a long-range mission is relatively high due to the large fuel load on board, designing a long-range STOL aircraft would impose severe penalties that would make the aircraft uneconomical. In setting the requirements for this study, I decided to compromise by having a long-range CTOL design mission, and a short-range STOL off-design mission. Since the smaller fuel load of a short, off-design mission lowers the takeoff weight, both wing loading and thrust-to-weight ratio improve, making the penalties for STOL capability considerably lower.

\section{Modeling}

While the Aeronautics Systems Analysis Branch at NASA Langley has had extensive experience with conceptual turbofan airliner design, the vast majority of this experience has been with conventional takeoff and landing (CTOL) designs. Because of this, nearly all of these designs have had the Federal Aviation Regulation (FAR) mandated second segment climb gradient as an active constraint during the takeoff phase, but neither takeoff nor landing field lengths have been active constraints, meaning that they were not discriminators that would change the outcome of a study. Our standard methodology for modeling and analyzing takeoff and landing has been adequate for the purposes of comparing different configurations and levels of technology on a consistent basis for CTOL aircraft. This standard methodology consists of using high-lift system performance that is representative of a CTOL turbofan airliner, but not specific to any one of the concepts being analyzed. Unfortunately, our standard methodology is inadequate for a STOL concept study because both takeoff and landing field lengths are, by definition, active constraints. Also, it was obvious that future work would require an in-house ability to assess new high-lift technologies, making reliance on the same, relatively old, high-lift performance data unacceptable. Twodimensional and three-dimensional aerodynamics tools were applied to the high-lift problem, with mixed results, as summarized very briefly below. These results were then applied to our standard process of modeling and analyzing conceptual aircraft designs, while emphasizing the unique characteristics inherent in STOL operations.

\section{A. Two-Dimensional Aerodynamics}

In order to break our dependency on external data, which is scarce and is almost always proprietary, as well as to create the ability to evaluate new high-lift technologies, I decided to follow a similar path similar to that proposed by Dr. Case Van Dam at the University of California at Davis. ${ }^{6}$ Essentially, the idea is to generate two-dimensional performance data for high-lift systems, use a linear, three-dimensional analysis to get local chord conditions, and then integrate to find total wing performance. This approach is very attractive because it allows two-dimensional data, regardless of source, to then be applied to specific wing planforms. 


\section{Energy Efficient Transport Airfoil Coords}
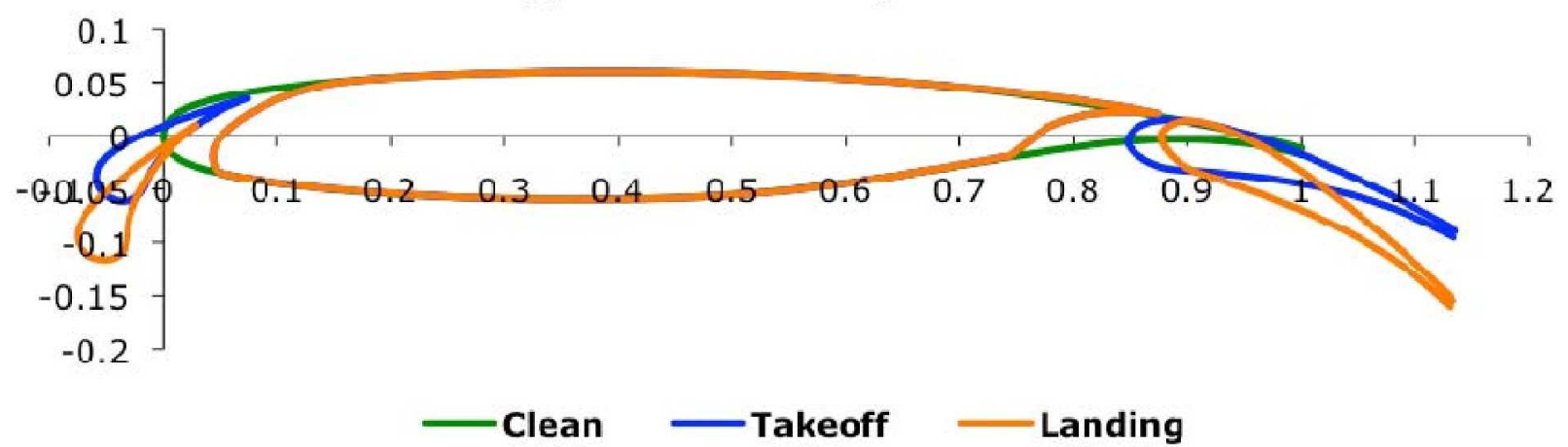

Figure 2. Energy Efficient Transport high-lift system coordinates.

The first step in this approach is to collect or generate the two-dimensional data. For this study, I chose an advanced high-lift system developed by NASA for the Energy Efficient Transport program (Fig. 2). This high-lift system was attractive because there was enough geometric information available to perform computational aerodynamics, and the design was not proprietary. It is a slat, main, single-slotted flap system that has maximum lift coefficients comparable to more complex multi-slotted flap systems.

There are several options for two-dimensional aerodynamic calculations. While there are many single-element airfoil analysis programs, this is a multi-element problem, which narrows the options significantly. Since I have had both experience and good results using Dr. Mark Drela's MSES airfoil program, I selected it for this study. ${ }^{7}$

For most of the analysis, MSES performed well; however, there is one area in which it became very difficult for MSES to converge on a solution (Fig. 3). This was near stall at the highest flap settings. This is understandable, given that at this condition there is a high degree of separation, and that the solution is extremely sensitive to what is

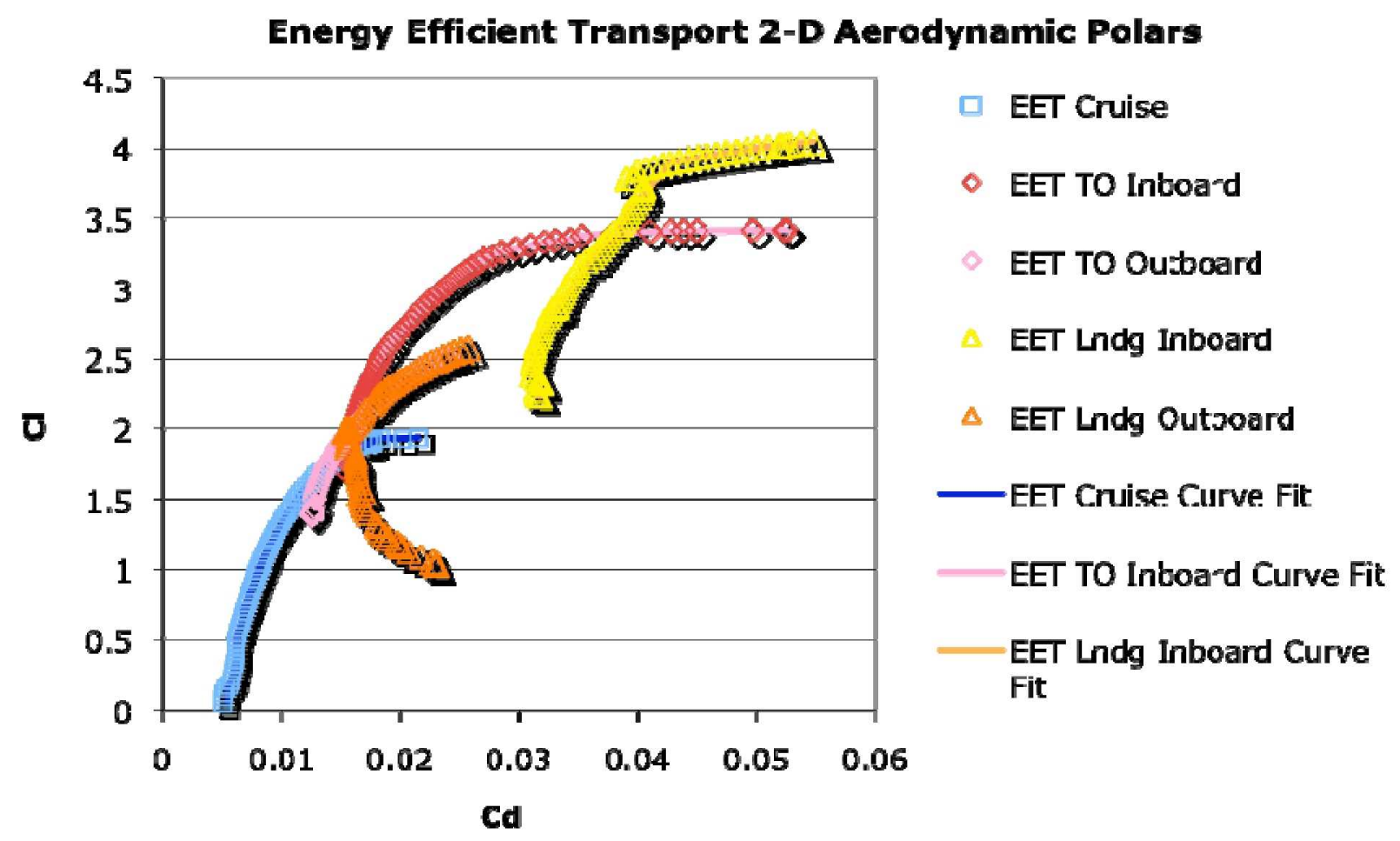

Figure 3. Energy Efficient Transport high-lift system 2-D aerodynamic results. 
likely to be a very chaotic separation location. Initially, this seemed to be a critical problem because the approach speed of an airliner is directly related to its maximum lift coefficient through regulation. Not being able to identify maximum lift coefficient for the two-dimensional flow meant that it could not be identified for three-dimensional flow either. However, there is some indication of approximately the value where stall occurs and later experience showed that landing field length was seldom an active constraint in the aircraft design, which meant that some inaccuracy could be tolerated and yet still not change the conclusion of the study. Also, the generous safety margins required by the Federal Aviation Administration (FAA) meant that no analysis of the takeoff or landing was performed anywhere near the stall condition, further minimizing the impact of this problem.

\section{B. Three-Dimensional Aerodynamics}

Once the two-dimensional aerodynamics estimate was completed, the next task was to correct it to account for planform and three-dimensional effects. After considerable difficulty in trying to develop a new program specifically for this problem, I finally decided to adapt a well-known vortex lattice aerodynamics program that could, with some effort and caveats, be applied. This program is VorView/VorLax (Fig. 4). ${ }^{8}$ After a protracted period of experimentation, I finally identified a reasonable process for estimating the highlift performance of a full aircraft configuration with trim. Unfortunately, I do not have access to enough data for a single configuration to validate the results of this process. What data I do have indicates that the overall process is reasonable at modest lift coefficients, but is most likely over-predicting drag at the highest lift coefficients. In the available test data, it appears that at the higher flap settings, as the real wing nears stall, it behaves progressively more like a low aspect ratio wing, whose span is approximately that of the flaps (Fig. 5). The vortex lattice method is insensitive to this effect. Instead of producing a more elliptical spanwise load distribution over the flap span, these methods may be

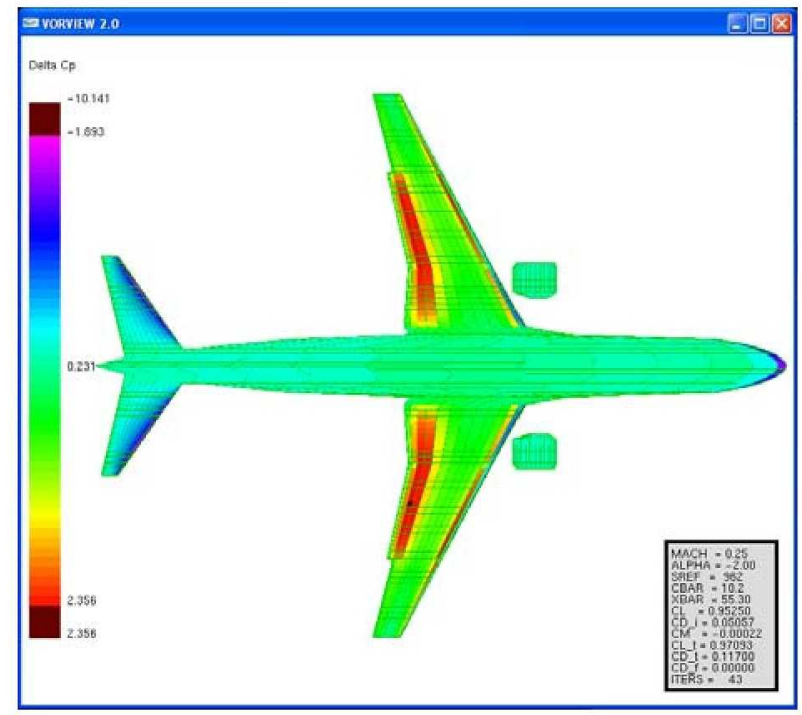

Figure 4. VorLax full configuration trimmed aero. over-estimating the outboard loading, raising some doubt as to the efficacy of the basic approach. While this is not what I had hoped for, once again the generous safety margins required by the FAA ensure that no takeoff or landing performance analysis takes place in the areas of greatest uncertainty. Also, this process may still be adequate for performing analysis of alternatives, which is the primary function of conceptual design, because it should not penalize an individual technology more than any other.

\section{Aircraft Model Validation and Calibration}

Although it is possible to perform a study using NASA Langley's Flight Optimization System (FLOPS) program completely in default mode, it is generally better to pick a representative aircraft which has enough data available publicly that it can be modeled in FLOPS, so that FLOPS may be tuned to ensure appropriate results for that class of aircraft. The class of interest for this study is a regional jet of approximately 100-seat capacity. A literature search indicated that the Embraer ERJ190AR was a very good match to the mission of interest and was newly in service, implying a state-of-the-art technology level. Over time, sufficient data sources became available allowing for a good match. ${ }^{9-12}$ As usual, some of the most critical data has not been, and probably will not be, made publicly available. These data concern characteristics such as airfoil coordinates, component weight breakdown, trimmed drag polars, detailed cruise conditions, and engine fuel flow. The analyst has to infer many details using judgment and experience to fill in the gaps.

Also, the analyst has to be aware that there will be discrepancies between different sources, even if they are all supplied by the manufacturer. Once a best set of validation data was compiled for the ERJ190AR, I then followed our standard procedure for modeling an existing aircraft. This meant identifying which available inputs I knew, which would require an assumption, and which I would have to modify in order to best reproduce known performance data. I had two colleagues review these inputs to ensure that they were accurate or reasonable to the extent of our knowledge. The initial weight and performance estimates were within $5 \%$ of the validation data set. However, the takeoff and landing field lengths were off by more than $20 \%$. 
Boeing 737-100 vs STOL RJ High-lift

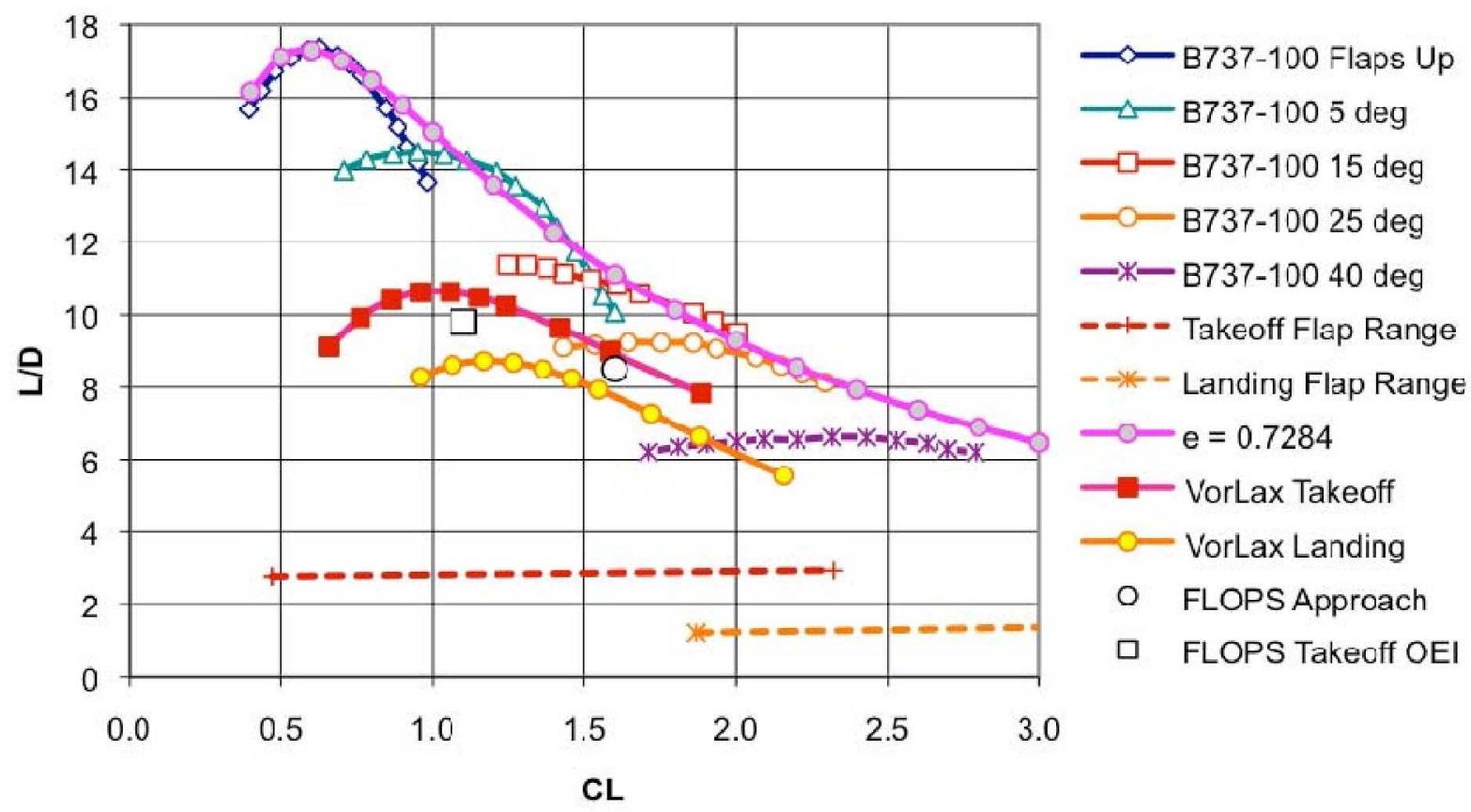

Figure 5. Boeing 737-100 and STOL RJ high-lift system 3-D aerodynamic results comparison.

There are two probable reasons for this discrepancy. The first reason is that takeoff and landing operations during the certification process do not really reflect normal operations in the field. For example, the FAA imposes special rules, such as not allowing the use of thrust reversers, even if they are available, because their reliability is deemed too low. Another example is that the FAR landing field length is based on the actual distance required during certification divided by 0.6 . This creates a strong incentive for the airframe manufacturer to perform the certification tests as aggressively as possible. When I modified the takeoff and landing parameters to reflect an aggressive pilot performance, most of the discrepancy between the published design takeoff and landing performance, and that estimated by FLOPS disappeared. The second probable reason is that the values originally input for the maximum lift coefficients for both takeoff and landing were inaccurate. Since these are values that are not available to me, and the high-lift system that is modeled is not exactly the same as that used by the ERJ190AR, I decided to tune the maximum lift coefficients in order to yield the takeoff and landing field lengths published by Embraer for the design mission. The values that resulted, 1.9 for takeoff and 2.8 for landing, appear reasonable. However, using the same values for the off-design mission's takeoff field length yields a somewhat higher value than that published. Embraer's published value is 4157 feet, while FLOPS estimates 4654 feet, which is approximately $12 \%$ higher. I could think of no reasonable changes to make in order to close this difference, so I decided to let it stand and work from this as the baseline.

\section{Aircraft Model Optimization Calibration}

All of the previous modeling was done in analysis mode in FLOPS. If the study for which this model was created does not entail any redesign, then this model is adequate. However, if the study does entail redesign, then an additional level of calibration is required. This additional calibration is particularly difficult to execute because the intent is to find a balance between the disciplines that will be affected by changing design variables, and the data necessary to validate success is unavailable.

This step is important because the primary focus of conceptual design is to perform an analysis of alternatives. An important part of this is to reduce errors due to inconsistency. This is actually more important than to reduce bias errors that may skew the actual value, but not the relative ranking of the concepts and technologies. One of the classic mistakes that analysts make is to match an aircraft in analysis mode, then apply configuration changes or technology factors, and then turn on the optimization to get the benefit. The problem with this is that some of that 
benefit is likely to be due to secondary errors in the model, and not due to the configuration changes or technologies of interest.

This study's design variables are: wing area, wing aspect ratio, and engine size. Simply using the optimizer with these design variables on the validation model yielded a $3 \%$ reduction in takeoff weight, a $12 \%$ reduction in fuel weight, a $12 \%$ increase in lift-to-drag ratio, a $4 \%$ reduction in design mission takeoff and landing field lengths, an $8 \%$ increase in wing area, a $19 \%$ increase in wingspan, a $31 \%$ increase in wing aspect ratio, and a $13 \%$ decrease in engine thrust. These are numbers that typically swamp the real effects of configuration changes and technology application. This is why it is so important to either take this step and then declare this "optimized" vehicle to be the baseline for all subsequent comparisons, or to take the additional step of optimization calibration.

Given such large artificial changes, I decided to try to bring the baseline back in line with the validation model. Doing this requires some assumptions. The analyst must assume that the design mission of the model is the same or very close to the design mission of the original aircraft, that the original aircraft is free from external drivers such as being compromised by being part of a large family, that the objective function used in the optimization will yield the same outcome as that used by the original manufacturer, and that the analysis methods accurately reflect the reality embodied by the original aircraft. While there is no guarantee that all of these conditions are met, it is worth trying to see if the baseline can be brought closer to the validation model.

Based on previous experience, I suspected that optimizing wing area only would be the easiest first step. This resulted in a wing area substantially larger than the validation model. Since the validation model was carrying 1914 lb. of unaccounted for empty weight, I modified the weight estimate of the wing to absorb all of this. This time, the optimizer returned almost exactly the same design as the original validation model. While not proof that the wing was the source of the unaccounted for empty weight, this is a strong indication that it probably was.

Next, I added wing aspect ratio as a design variable. This time the optimizer returned a wing that had much higher aspect ratio than the validation model. This is something that we've seen many times in the past. It indicates to me that the detailed structural weight estimation in FLOPS significantly underestimates the amount of wing weight related to bending. While total weight was fine after the first calibration, the balance between primary, secondary, and miscellaneous structural weight does not appear to be valid for this class of vehicle. I then modified these weight estimates until the optimizer returned a design that was very close to the validation model.

Last, I added engine scale as a design variable. Once again, the optimizer returned a design that was significantly different from the validation model. This time the parameter that appeared to be the problem was the takeoff field length constraint. The optimizer was trading increased takeoff field length in order to obtain a smaller engine. In an unconstrained design, with the freedom to size the engine, this is probably what the correct answer is. However engines come in very specific sizes and so the ERJ190AR takeoff field length performance was most likely a fallout, given their engine choice. In order to see if the optimizer would come back with the validation model, I adjusted the maximum takeoff field length allowed to be that achieved by the validation model. The optimizer returned a design that yielded a $1.6 \%$ reduction in takeoff weight, a $6 \%$ reduction in fuel weight, a $6 \%$ increase in lift to drag ratio, a $5 \%$ reduction in design mission landing field length, a $9 \%$ increase in wing area, a $9 \%$ increase in wingspan, a $9 \%$ increase in wing aspect ratio, and a $10 \%$ decrease in engine thrust. While these changes are significant, they are much less now that the optimization calibration has taken place. It is at this point that this model becomes the CTOL baseline against which all other designs are compared.

\section{E. Aircraft Model Design}

Now that the CTOL baseline is complete, analysis can be performed to quantify the effect of changes in requirements, configuration, and technologies. This section will analyze the effect of requiring incrementally shorter takeoff and landing distances on the baseline configuration. The objective function is to minimize gross weight, subject to several constraints, many of which are related to the takeoff and landing, and the design variables are as mentioned before: wing area, wing aspect ratio, and engine scale.

Since FLOPS does not have the ability to constrain the off-design mission takeoff and landing field lengths, I had to adjust the design mission takeoff and landing field lengths in order to achieve the desired values in the offdesign mission through repeated manual adjustment.

The field lengths of interest are: 4000 feet, 3500 feet, and 3000 feet. Each desired field length had a new aircraft designed to meet the requirement.

As expected, the 4000 foot constrained design had very little penalty in relation to the baseline. This is because the landing field length was already acceptable, and the takeoff field length required was only $13 \%$ less. The optimizer returned a design that yielded a $1.3 \%$ increase in takeoff weight, a $3 \%$ increase in fuel weight, a $2 \%$ decrease in lift-to-drag ratio, a $14 \%$ increase in wing area, a $2 \%$ increase in wingspan, an $8 \%$ decrease in wing aspect ratio, and a $3 \%$ increase in engine thrust. 
The 3500 foot constrained design understandably had more penalty in relation to the baseline. This is because the takeoff field length required was $24 \%$ less and meeting this requirement was more stringent than the landing requirement. The optimizer returned a design that yielded a $3 \%$ increase in takeoff weight, a $6 \%$ increase in fuel weight, a $3 \%$ decrease in lift-to-drag ratio, a $29 \%$ increase in wing area, a $5 \%$ increase in wingspan, a $15 \%$ decrease in wing aspect ratio, and a $7 \%$ increase in engine thrust.

The 3000 foot constrained design understandably had the most penalty in relation to the baseline. This is because the takeoff field length required was $35 \%$ less. Interestingly, the landing field length requirement became active at this distance, meaning that the performance needed to be balanced between the two requirements for the first time. The optimizer returned a design that yielded a $6 \%$ increase in takeoff weight, a $7 \%$ increase in fuel weight, a $2 \%$ decrease in lift to drag ratio, a $58 \%$ increase in wing area, a $17 \%$ increase in wingspan, a $13 \%$ decrease in wing aspect ratio, and an $11 \%$ increase in engine thrust.

It is clear from these designs that the optimizer prefers to add wing area instead of increasing engine size. This indicates that the wing is relatively inexpensive compared to the engine on a gross weight basis, and suggests that technologies relating to the engine would probably have a greater effect on a STOL RJ.

\section{Future Work}

Having established the penalties associated with STOL requirements on a contemporary conventional RJ configuration, this is a good basis from which to assess the impacts of advanced technologies on this class of vehicle. Future plans are to automate the use of the off-design mission takeoff and landing field length constraints, to employ an advanced ultra-high-bypass turbo fan engine which not only will be sized, but the engine cycle will be modified, as well as the usual sensitivities to weight reductions for structure, and the impact of natural laminar flow. The most difficult technology to apply will be that of circulation control. While the high-lift performance assessment used in this study for passive lift should be able to estimate the performance of powered lift, the real challenge will be modifying our analysis to include a feedback loop to engine performance so that it is kept in synchronization with the air bleed requirements to power the circulation control system.

\section{Conclusion}

A conceptual design study was performed for a modern, conventional short takeoff and landing (STOL) regional jet (RJ). New application of existing analysis programs was somewhat successful in estimating high-lift aerodynamic performance specifically for the takeoff and landing phases of flight. While there is room for improvement, the fidelity achieved appears to be adequate for the primary purpose of conceptual design, which is to analyze alternatives in order to identify the best combinations of configuration and technologies.

The penalties resulting from reducing the takeoff and landing field lengths for a 100 passenger class STOL RJ have been quantified. While this study has not attempted to quantify what operational benefits may come from the increased capability, these results could be used in such a study to determine whether or not those benefits outweigh the costs. 
Appendix: Study Model Summary Data

\begin{tabular}{|c|c|c|c|c|c|c|c|c|c|c|}
\hline Aircraft & Units & Reported & Validation 03 & $\begin{array}{l}\text { Calibration } \\
04 \mathrm{~b}\end{array}$ & $\begin{array}{l}\text { Calibration } \\
\text { 05b }\end{array}$ & $\begin{array}{c}\text { Calibration } \\
\text { O6b } \\
\text { CTOL RJ } \\
\text { Baseline }\end{array}$ & $\begin{array}{l}\text { STOL RJ } \\
4.0 \mathrm{k}\end{array}$ & $\underset{3.5 k}{\text { STOL RJ }}$ & $\underset{3.0 \mathrm{k}}{\text { STOL RJ }}$ & $\begin{array}{l}\text { Design 03b } \\
\text { Optimized } \\
\text { w/o } \\
\text { calibration }\end{array}$ \\
\hline Source & & Embraer & FLOPS & FLOPS & FLOPS & FLOPS & FLOPS & FLOPS & FLOPS & FLOPS \\
\hline \multicolumn{11}{|l|}{ Weights: } \\
\hline Maximum Ramp Weight & lb & 114,552 & 114,551 & 114,547 & 114,233 & 112,646 & 114,075 & 115,850 & 119,188 & 111,366 \\
\hline Mission Takeoff Gross Weight & $\mathrm{lb}$ & 111,534 & 111,533 & 111,529 & 111,223 & 109,678 & 111,069 & 112,798 & 116,048 & 108,432 \\
\hline Maximum Landing Weight & Ib & 97,003 & 97,003 & 96,999 & 96,733 & 95,389 & 96,599 & 98,103 & 100,929 & 94,306 \\
\hline Basic Operating Weight & Ib & 61,333 & 61,333 & 61,332 & 61,337 & 61,300 & 61,988 & 62,895 & 65,697 & 61,557 \\
\hline Mission Payload & Ib & 21,605 & 21,605 & 21,605 & 21,605 & 21,605 & 21,605 & 21,605 & 21,605 & 21,605 \\
\hline Maximum Fuel Weight & lb & 28,596 & 28,600 & 28,612 & 28,310 & 31,373 & 39,730 & 49,815 & 66,765 & 27,944 \\
\hline Mission Fuel Weight & Ib & 28,596 & 28,595 & 28,592 & 28,280 & 26,773 & 27,476 & 28,298 & 28,746 & 25,270 \\
\hline Wing Primary Structure Weight & lb & $?$ & 3,494 & 4,184 & 7,207 & 7,970 & 7,626 & 7,296 & 8,375 & 5,001 \\
\hline $\begin{array}{l}\text { Wing Secondary Structure Weight } \\
\text { Wing Miscellaneous Structure }\end{array}$ & lb & $?$ & 5,010 & 6,000 & 3,228 & 3,298 & 3,473 & 3,656 & 3,984 & 5,054 \\
\hline Weight & lb & $?$ & 1,168 & 1,399 & 1,171 & 1,336 & 1,623 & 1,954 & 2,648 & 1,307 \\
\hline Empty Weight Margin & Ib & ? & 1914 & 0 & 0 & 0 & 0 & 0 & 0 & 1914 \\
\hline Design Mission Range & nm & 2,400 & 2,400 & 2,400 & 2,400 & 2,400 & 2,400 & 2,400 & 2,400 & 2,400 \\
\hline Altitude for Design Mission & $\mathrm{ft}$ & $?$ & 37,408 & 37,414 & 37,510 & 38,198 & 38,222 & 38,463 & 38,210 & 38,886 \\
\hline Altitude for $500 \mathrm{~nm}$ Mission & $\mathrm{ft}$ & 35,000 & 35,000 & 35,000 & 35,000 & 35,000 & 35,000 & 35,000 & 35,000 & 35,000 \\
\hline Maximum Operating Speed & Mach & 0.82 & 0.82 & 0.82 & 0.82 & 0.82 & 0.82 & 0.82 & 0.82 & 0.82 \\
\hline Economic Cruising Speed & Mach & 0.78 & 0.78 & 0.78 & 0.78 & 0.78 & 0.78 & 0.78 & 0.78 & 0.78 \\
\hline Start of Cruise LID & & $?$ & 15.88 & 15.88 & 16.06 & 16.81 & 16.54 & 16.30 & 16.44 & 17.84 \\
\hline Takeoff Field Length @ MTOW & $\mathrm{ft}$ & 6,745 & 6,745 & 6,742 & 6,649 & 6,744 & 5,840 & 5,078 & 4,282 & 6,432 \\
\hline Takeoff Wing Loading @ MTOW & $\mathrm{lb} / \mathrm{ft}^{\wedge} \mathbf{2}$ & 112.0 & 107.6 & 107.6 & 107.1 & 96.8 & 86.1 & 77.2 & 64.9 & 97.0 \\
\hline Takeoff ThrustWeight @ MTOW & & 0.359 & 0.359 & 0.359 & 0.360 & 0.327 & 0.332 & 0.340 & 0.344 & 0.320 \\
\hline Landing Field Length @ MLW & $\mathrm{ft}$ & 4,341 & 4,342 & 4,341 & 4,336 & 4,119 & 3,869 & 3,657 & 3,280 & 4,150 \\
\hline \multicolumn{11}{|l|}{ Fallout Mission Performance: } \\
\hline FO Mission Takeoff Gross Weight & Ib & ? & 93,195 & 93,193 & 93,144 & 92,518 & 93,446 & 94,656 & 97,680 & 92,384 \\
\hline Takeoff Field Length for $500 \mathrm{~nm}$ & $\mathrm{ft}$ & 4,157 & 4,644 & 4,642 & 4,625 & 4,598 & 3,999 & 3,495 & 3,010 & 4,761 \\
\hline Takeoff Wing Loading for $500 \mathrm{~nm}$ & $\mathrm{lb} / \mathrm{ft}^{\wedge} \mathbf{2}$ & $?$ & 89.9 & 89.9 & 89.7 & 81.6 & 72.4 & 64.8 & 54.6 & 82.7 \\
\hline Takeoff ThrustWeight for $500 \mathrm{~nm}$ & & $?$ & 0.429 & 0.429 & 0.429 & 0.388 & 0.394 & 0.405 & 0.409 & 0.375 \\
\hline $\begin{array}{l}\text { Landing Field Length for } 500 \mathrm{~nm} \\
\text { Geometry: }\end{array}$ & $\mathrm{ft}$ & $?$ & 3,937 & 3,937 & 3,937 & 3,763 & 3,542 & 3,358 & 2,950 & 3,809 \\
\hline Reference Wing Area & $\mathrm{ft2}$ & 996.0 & 1036.4 & 1036.7 & 1038.1 & 1133.4 & 1290.7 & 1460.5 & 1788.8 & 1117.5 \\
\hline
\end{tabular}

American Institute of Aeronautics and Astronautics 


\section{References}

1"Hartsfield - Jackson Atlanta International Airport," AirNav.com [online database], URL: http://airnav.com/airport/KATL [cited 26 February 2008].

2"Dekalb-Peachtree Airport," AirNav.com [online database], URL: http://airnav.com/airport/PDK [cited 26 February 2008 ].

${ }^{33 " C o b b}$ County Airport-McCollum Field," AirNav.com [online database], URL: http://airnav.com/airport/RYY [cited 26 February 2008].

4"Fulton County Airport-Brown Field," AirNav.com [online database], URL: http://airnav.com/airport/FTY [cited 26 February 2008].

5"Berry Hill Airport," AirNav.com [online database], URL: http://airnav.com/airport/4A0 [cited 26 February 2008 ].

${ }^{6}$ Van Dam, C. P., Vander Kam, J. C., and Paris, J. K., "Design-Oriented High-Lift Methodology for General

Aviation and Civil Transport Aircraft," AIAA Journal of Aircraft, Vol. 38, No. 6, 2001, pp. 1076-1084.

${ }^{7}$ Drela, M., "Design and Optimization Method for Multi-Element Airfoils," AIAA 93-0969, AIAA, Reston, VA, 1993.

${ }^{8}$ Miranda, L. R., Elliott, R. D., and Baker, W. M., "A Generalized Vortex Lattice Method for Subsonic and Supersonic Flow Applications," NASA CR-2865, 1977.

${ }^{9}$ Empresa Brasileira de Aeronáutica S.A. (Embraer), "FAA Type Certificate Data Sheet NO. A57NM," Department of Transportation, Federal Aviation Administration, A57NM Revision 8 Embraer, 2005.

${ }^{10}$ Empresa Brasileira de Aeronáutica S.A. (Embraer), "Embraer 190 Airport Planning Manual," APM-1901, Embraer S. A., Sao Jose Dos Campos, 2005.

${ }^{11}$ Empresa Brasileira de Aeronáutica S.A. (Embraer), “The Answer is E," 1934_spec190.indd Product Brochure, Embraer S. A., Sao Jose Dos Campos, 2007.

${ }^{12}$ Empresa Brasileira de Aeronáutica S.A. (Embraer), "Type Certificate Data Sheet NO. 2005T13-05," Agencia Nacional De Aviacao Civil - Brazil, 2008. 